\title{
Using Technology to Transform Communities of Practice into Knowledge-Building Communities
}

\author{
Christopher M. Hoadley \\ College of Education, and School of Information \\ Sciences \& Technology \\ Penn State University \\ 314D Keller Bldg. \\ University Park PA 16802 \\ +1 (814) 863-0415 \\ siggroup05@tophe.net
}

\author{
Peter G. Kilner \\ Instructional Systems Program \\ Penn State University \\ 315 Keller Bldg. \\ University Park PA 16802 \\ +1 (814) 769-9329 \\ pgk111@psu.edu
}

\begin{abstract}
Knowledge and learning exist as byproducts of social processes such as those that take place in communities of practice. We describe two frameworks for understanding and building online knowledge-building communities, or online communities of practice that enhance collective knowledge. First, the C4P framework is described as a way of understanding how knowledge is created and disseminated by participants in a community of practice. Second, we discuss ways in which technology provides added value for learning in these environments using the DDC (Design for Distributed Cognition) framework, and link this to the particular goals of a knowledgebuilding community. Examples from two large online communities are discussed.
\end{abstract}

\section{Categories and Subject Descriptors}

K.3.1 [Computing Milieux]: Computer Uses in Education distance learning, collaborative learning.

\section{General Terms}

Design, Human Factors, Theory.

\section{Keywords}

Community of practice, knowledge building, online community, design, distributed cognition, learning, context, conversation, social networks, CompanyCommand, CILTKN.

\section{INTRODUCTION}

How can we design online communities for knowledge building? This paper provides two theoretical frameworks that help answer this question: the C4P model of learning in communities, and the Design for Distributed Cognition (DDC) framework for creating learning with technology. First, we

\footnotetext{
Permission to make digital or hard copies of all or part of this work for personal or classroom use is granted without fee provided that copies are not made or distributed for profit or commercial advantage and that copies bear this notice and the full citation on the first page. To copy otherwise, or republish, to post on servers or to redistribute to lists, requires prior specific permission and/or a fee.
}

examine the literature on online communities, learning, and knowledge-building. Second, we introduce two frameworks: one describes knowledge-building processes in a community of practice (CoP), and the other describes the role technology can play in such a community. Finally, we use these two frameworks to discuss answers to the opening question, using two large online communities as examples. Design implications are outlined.

In the sections below, we describe the phenomenon of a community of practice, and show how learning is intimately related to these communities. We describe how one type of community of practice, the knowledge-building community, is particularly aimed at the creation and learning of knowledge, and we highlight the current trend toward building such communities online.

\subsection{Relationship between Learning and Community}

What is the relationship between learning and community? We can examine this question from the point of view of learning and ask what role community plays. In addition, we can examine communities and ask what role learning plays.

Modern learning theories support the value of communities as a setting for learning. Modern learning theories are generally agreed to provide four major models for how learning takes place, in addition to the naïve theory of knowledge transmission. (Knowledge transmission reduces learning to a simple case of communicating information; however, this model overlooks the difficulty inherent in comprehension.) These four theories are behaviorist learning, developmental learning, cognitive learning, and sociocultural learning. Behaviorist learning theory generally explains learning as the result of conditioned responses, while developmental learning theory explains learning as a result of interaction with the world plus biologically mediated maturation processes [6]. Cognitive learning theory generally explains learning as the result of active cognitive processes that yield new mental representations and predispositions. Both developmental learning theory and cognitive learning theory are often labeled "constructivism," emphasizing that learners must construct their own understanding of the world [46]. A final model of learning is sociocultural learning theory, which views learning as a result of appropriation of social practices [36, 58]. These models overlap in many cases, and to some extent depend on the 
definition of learning (learning as changed behavior vs. developmental changes vs. changed mental representations vs. changed social practices.)

Learning theories help the designers of learning environments understand what they are fostering. No matter which learning theory the designer ascribes to, communities can provide opportunities for learning. For instance, consistent with the behaviorist tradition, interaction with others in a community can be the feedback that conditions responses to stimuli. Likewise, in the developmental tradition, interaction with peers and nearpeers in a community may provide developmentally appropriate scaffolding. In the cognitive learning tradition, participating with others in groups can provide an opportunity to generate explanations, which results in deeper individual cognitive processing and hence, better learning [7]. Clearly, communities provide fertile ground for sociocultural appropriation (adopting expert practices through social processes) as well. In sum, communities could be a venue for learning regardless of the learning theory to which the designer ascribes.

Indeed, we can also ask what role learning plays in understanding communities. Lave and Wenger [37] discuss the reciprocal relationship between communities and learning. To endure, communities need to replicate themselves by enculturating new members through learning. As newcomers arrive in a community, they participate peripherally in its practices. Over time, their participation can become more central as their practices become more expert-like and their identities more entwined with community membership. Learning, then, is a natural byproduct of communities.

To sum up, from a theoretical point of view, communities can support learning according to the major learning theories, and indeed the very existence of enduring communities relies on learning. Can we capitalize on this relationship between learning and community for educational purposes?

\subsection{Why all Learning isn't Educationally Valuable}

Although education and learning are linked, it is easy to forget that learning-desirable or undesirable-takes place all the time, in every setting. Individuals naturally adapt to the demands of their environment, and this takes place whether one is learning something valued by others or not. In the worst cases, individuals learn helplessness [45]; in the best cases, they learn what helps them achieve their personal goals in authentic contexts. In schooling or educational settings, we hope that learners achieve the learning goals designed into the learning environment. In the degenerate case, students instead learn how to "game" schooling. For instance, instead of learning how to perform math techniques correctly for certain kinds of problems, students may learn that "applying whatever technique was most recently taught will make the teacher happy." Thus, if we wish to educate, we must be careful to distinguish between fostering desired learning from fostering learning indiscriminately. Our task is to identify ways we can deliberately foster positive kinds of learning.

Sociocultural learning theory can be applied to model either type of learning: deliberate education and accidental adaptation. This theory is based on a particular kind of community, the community of practice. Communities of practice are stable groups of people with a shared set of cultural practices. Frequently, they involve peers (either professional or social) although they may be more hierarchical. Although members may come and go over time, CoPs have a relatively stable set of practices that help define membership in the group [37]. Thus, a group of people who happen to live in the same town but do not interact or share common practices would not constitute a CoP. However, a group of people who interact online anonymously might be a $\mathrm{CoP}$ if they have stable practices that are shared, even if the members of the community do not know each other in a face-to-face setting.

Just as schooling may engender learning outcomes we do not value, communities of practice may produce undesirable learning. A more sinister example of a community of practice might be organized crime, in which participants learn how to be better and more ruthless criminals by adopting the practices of the group.

Even though learning takes place in communities of practice, it does not have to be the explicit goal of the community, nor does the community need to be school-like. In a classic example of sociocultural appropriation, Orr described photocopier repair technicians in a community of practice [43]. In effect, these technicians were sharing knowledge in order to support their more authentic practice-developing a professional identity through valued competence at work. Learning was simply a way in which the participants in this community adapted to life in the group. Indeed, participants viewed their participation as part of being a member of the profession-in short, they were learning to work, not working to learn [59].

Is there a particular kind of community of practice that aligns with what we think of as education? One that intentionally builds educationally valued knowledge? In a word, yes. Knowledge-building communities are a particular kind of community of practice focused on learning. Based on scholarly communities, knowledge-building communities take as an explicit goal the development of individual and collective understanding. Such communities are not limited to scholars or researchers. On the contrary, many argue that the development of knowledge-intensive work pushes all professions towards knowledge-building [16, 50,56]. A group of scientists in a research lab might be both a community of practice and a knowledge-building community; likewise, a group of children at an after-school computer club could be a knowledge-building community, if their shared goals and practices are oriented towards knowledge creation and learning. Knowledge-building communities, then, are a possible way to exploit communities of practice for educational aims.

\subsection{Knowledge Building beyond Schooling: A Systemic View of Knowledge}

The combination of learning theory and the idea of communities of practice has brought forth a new model of knowledge. Instead of the traditional idea of information as knowledge, we see knowledge as a systemic property of people in communities. There is an ebb and flow between tacit and explicit as the knowledge is constructed by individuals, shared, and reconstructed by someone else [15, 42]. Information flows not only in formal monologues such as textbooks or MIS systems, but also in dialogues among groups of people - the primary way 
information is converted to knowledge [25]. In short, knowledge is the byproduct of the social life of information as it impinges on individuals and changes them [5]. In this view, knowledge is both individual and collective, and it has profound implications for knowledge management and institutional memory in any business or profession. In these contexts, communities of practice generally, and knowledge-building communities particularly, can be engines for the creation and dissemination of knowledge.

Although desirable knowledge and learning might occur without intervention, they are greatly accelerated in communities of practice, especially knowledge-building communities. Thus, fostering knowledge-building communities might be a goal for many people: for teachers who try to orchestrate collaborative learning; for institutions interested in knowledge-management; for professionals trying to advance their field; and for organizations trying to foster knowledge generation in an information economy.

\subsection{Taking it Online: The Growth of Online Communities as an Educational Tool for Knowledge-Building}

Technology has an important role to play in supporting knowledge-building communities and communities of practice in general. In the past decade since widespread adoption of the World-Wide Web, a number of important social phenomena have arisen. The ease of asynchronous, distal communication (and synchronous, distal communication) has influenced many aspects of society; we now have e-business, e-government, and e-learning. While many of these phenomena can take place on an individual level, in other cases, the "killer app" has been the use of technology to support groups of people [19, 60, 62, 63], most notably online communities [48]. Although online communities have a variety of raisons d'être, ranging from medical support groups to online dating, one of the more promising reasons for online communities is as a support for knowledge-building communities. Online communities can provide a forum where information may be exchanged, and are often a component of online learning environments [21, 23]. Indeed, even as groupware has been invented to support work (as in the field of computer-supported cooperative work, or CSCW), it has also been created to support learning (as in the field of computer-supported collaborative learning, or CSCL). Indeed, because learning and social interaction are tightly intertwined, it is difficult to examine virtual communities without also involving concepts of change and learning, blurring the historical distinctions between CSCW and CSCL (e.g., [1, $11,32,47,60])$.

\subsection{Summary}

In the sections above, we have described the phenomenon of a community of practice, and have shown how learning is intimately related to these communities. We have linked learning with communities of practice and described how one type of community of practice, the knowledge-building community, is particularly aimed at the creation and learning of knowledge.

How can we design knowledge-building communities, and what role can technology play? In the sections that follow, we begin to answer these questions by examining a model of how learning takes place in CoPs, and a design framework for fostering learning through technology. Combining these frameworks provides some insight in what might be required to support online knowledge-building communities.

\section{LEARNING IN A COMMUNITY OF PRACTICE: THE C4P MODEL}

In this section, we present a model of how learning takes place in knowledge-building communities. This model developed from the experiences gained in two such communities.

The C4P framework posits that knowledge is generated and shared when there is purposeful conversation around content in context. C4P is shorthand for content, conversation, connections, (information) context, and purpose. These elements comprise a non-linear system that occurs in a community of practice. An increase in any of the elements tends to result in increases in all of them, although the relationships are not one-to-one. Our proposal is that the greater that these elements are present in any community, the more likely and effective the knowledge generation and transfer will be.

The C4P framework defines each of these terms in a specific way. Content refers to explicit, static knowledge objects such as documents or video clips, whereas conversation refers to faceto-face or online discussions. The key distinction between content and conversation is that content involves a one-way communication of information (monologue), whereas conversation necessarily includes at least a two-way exchange of information (dialogue) [25]. Connections, as used in C4P, refer to interpersonal contacts between community members that involve some level of relationship. When one member sends an email to another member, a connection has occurred. Information context is the who, what, where, when, why, and how that enables community members to assess whether and how information is relevant to them. This context provides the richness of detail that makes information meaningful and memorable. Finally, purpose is the reason for which the members come together in the community.

The five elements of $\mathrm{C} 4 \mathrm{P}$ feed of and reinforce each other. For example, content shapes conversations and fosters connections. Conversation generates new content and adds context to existing content. Connections spark conversations and add context to content. Information context connects content to related content and to the community's purpose. Purpose provides the metaconnection between all the other elements.

All five elements are important to effective knowledge building in an online community. If content is absent, conversation is likely to have difficulty getting started and staying focused on the community's purpose. If conversation is missing, knowledge may transfer but is unlikely to be generated. If connections are absent, there will be fewer contributions of content and conversation, and the contributions will have less context. If information context is absent, the community is prone to misinterpret content or apply knowledge inappropriately to new situations. Finally, without purpose, knowledge building will founder. A clear communal purpose gives meaning to content, provides direction to conversation, fosters connections, and is the unifying context for all activities in the community.

The following sections will provide more explanation of what each of the elements are, why they are important to a 
knowledge-building community, and how they interact as a system.

\section{C4P Framework for Communities of Practice}

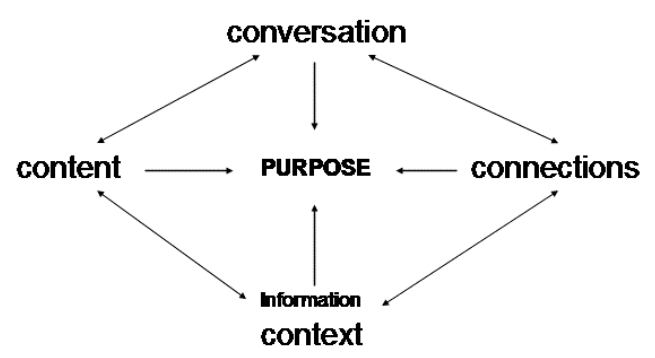

\subsection{Content}

Quality content is foundational to a knowledge-building community. Content serves four important purposes: it attracts members by providing immediate value; it socializes new members by implicitly communicating what kinds of topics and voices are appropriate; it serves as a basis for conversation; and, it motivates members as they see themselves jointly building their domain of knowledge.

Generating quality content, however, is one of the great challenges of nurturing a knowledge-building community. For a variety of reasons, people are hesitant to contribute content [9, 17]. The other elements of C4P help to address this challenge and facilitate content generation. For example, a community leader's connection with a member creates the conditions where she knows the member's competencies and can ask him for a specific contribution; people are much more likely to contribute when asked to. Another way to generate content is to repackage a conversation or series of conversations about a particular topic into a new object of content.

\subsection{Conversation}

Conversation is the most effective mode of knowledge transfer and generation, because the personal connection and back-andforth nature of conversation provide the greatest context for information [1]. The challenge within a knowledge-building community is to generate conversations that draw out meaningful knowledge, not aimless chatter.

Meaningful conversation is fostered by quality content, clear purpose, and personal connections. Content drives conversation. Conversation that is focused on a piece of content is likely to build upon that existing knowledge, and as long as the content under discussion is relevant to the community's purpose, the conversation is likely to be so, too. Moreover, a clear sense of shared purpose within the community fosters a culture of productive conversation, where everyone involved understands that the goal of every conversation is to support the purpose, not just to talk for talk's sake. Finally, connections within the community develop a culture of trust in which members feel safe to challenge each other's assumptions, float unconventional ideas, and introduce the "half don't knows" [11] that lead to breakthroughs in learning.

\subsection{Connections}

Connections are the lifeblood of a knowledge-building community. Without connections, an online space is merely a document repository (content) or chat room (conversation). Connections foster the relationships and subsequent trust that enable distributed people to work together on the common goal of building their knowledge domain [50].

Connections, as important as they are, do not just spontaneously occur in an online community. They can, however, be facilitated by the other elements described by $\mathrm{C} 4 \mathrm{P}$. For example, when a community has a clear purpose, its members know that they all share at least one thing in common with each other-passion for that purpose. That shared purpose reduces barriers to forming connections. Also, quality content and conversation facilitate member connections. When content and conversation are linked to the member profiles of those who contributed the knowledge, other members get to know the contributors and become more likely to connect with them.

\subsection{Information Context}

Information context enables learners to learn more efficiently and effectively [4]. Information context helps a community member know where a knowledge object came from and how it has been applied in the past-it might consist of information about the creator of a knowledge object and his or her situation, or it might be details, cross-references, or stories that allow a particular knowledge object to be interpreted. Information context empowers members of a community to understand what a contributor is communicating, to judge whether the information applies to them, and to apply the knowledge to their own situations.

A great challenge in a learning community is to situate knowledge among people who are not physically co-located. The elements described by the C4P framework, however, help members understand the context of information. A community's purpose, for example, should inhere in every piece of content, every conversation, every connection-it answers the question, "Why?" thus providing very valuable context. Also, when a conversation builds upon content, or when a member attaches content into a conversation, the result is greater context for everyone involved. Finally, when members are connected through a relationship, they gain access to context about each other's contributions to the community.

\subsection{Purpose}

Clarity of purpose creates energy and produces results. Shared purpose, indeed, is a defining factor in collaboration and community $[8,65]$. It alone has the ability to relate everything that occurs within the community, and shared purpose is a giant step to generating trust and connections.

Even if a community of practice has a stated purpose, its actual purpose will inhere in its content, conversations, connections, and context. Ideally, the actual and stated purposes are identical. Because the elements of C4P build off each other, the more focused a community's purpose is, the more likely it is that the 4Cs will support that purpose. Conversely, every piece of content, every conversation, every additional element of context 
serves either to reinforce or to undermine the community's stated purpose.

In sum, the C4P model provides an explanation of learningrelated processes that have occurred in several successful knowledge-building communities of practice [11]. Further empirical work is needed to elaborate the ways the components manifest themselves in different kinds of communities, and the mechanisms by which all five components reinforce each other.

\section{SCAFFOLDING KNOWLEDGE BUILDING WITH TECHNOLOGY: THE DESIGN FOR DISTRIBUTED COGNITION FRAMEWORK}

In this section, we explore another framework, this time for supporting the design and implementation of technology for learning with a distributed cognition approach. Distributed cognition explicitly encompasses not only cognitive phenomena that might take place in the head (mental representations, human information processing) but also representations and phenomena that take place in the world, between and among people in a social system $[29,51]$.

Designing for distributed cognition is different than designing for individual cognition, as represented not only in the humancomputer interaction literature but also in the cognitive science literature $[12,20,22,38]$, requiring different research, evaluation, and design methodologies. This distinction has cropped up not only with respect to design of CSCW (computersupported collaborative work) but also with respect to design of CSCL (e.g. [44]). Briefly, the core challenge is that design decisions in a distributed cognitive system have to respect not only individual psychological constraints and realities, but also systemic realities. Designers are challenged to comprehend and make simplifying assumptions about such a complex system.

The design for distributed cognition framework (formerly called the C-P-C framework, [27]) was developed in 1998 by analyzing examples of successful and innovative information technologies for learning, and historical trends in applications of computer tools to education, including various technologysupported constructivist and instructionist learning environments in a wide number of domains (see, for instance, [39]). By examining successful examples that worked both for individuals and for groups, it was hoped that the complexity of understanding distributed cognitive systems via first principles could be sidestepped, and appropriate design simplifications could be achieved by letting natural evolution do the work of weeding out examples that failed to meet both sets of criteria. In particular, the framework was developed by asking the question, "What is the special value added by technology when used as part of best practices in education?" Domain-specific advantages were excluded (especially the advantages provided by using technology in developing computer-skills). Certain historically proposed but currently suspect justifications for computer use were excluded, including programming skills as "the new Latin" (i.e., programming as a vehicle to domain-independent critical thinking), computers as a general motivational tool (due to their novelty at the time), and computers as productivity tools in support of the institutions of learning but not learning activities themselves (for instance, payroll systems for school districts). This last exception was perhaps the most difficult to delineate, since student information management systems often support activities like taking attendance or providing students and parents with assessment feedback. Corporate learning management systems may similarly blur the distinction between technology in support of learning and technology in support of finance or other organizational goals. While this category was excluded from the framework since the average educational technologist does not have management information systems or student information management systems in their purview, it remains an important part of how technology is currently impacting education.

The design for distributed cognition framework identifies three classes of advantages that technology can provide to learning environments: a representational advantage, where information technology provides access to novel representations of information in support of learning; a process advantage, where technology supports or facilitates learner tasks or activities; and a social context advantage, where technology shifts the social context in which the learning takes place, changing either relationships between people or relationships to self. These three categories are discussed more below.

\subsection{Representational Support}

The first class of advantages provided by information technology is the representational advantage. Computer technology provides enormous flexibility and new ways to represent information [26, 33, 34]. Even at the beginning of the personal computing revolution, multimedia (then in the form of audio-visual technology) was seen as having a significant advantage merely because of the ability to present information in multiple forms [54]. As technology has advanced, the flexibility of representing concepts has increased; now even low-end computers such as handheld devices can present text, images, sounds, and in many cases video. This unlocks the potential to present information in multiple forms, appealing to a dual coding model for learning [40]. It also permits a much greater type of interactivity with the user and contingency on user actions, with feedback provided real time [53]. Modern educational technology applications that take advantage of this approach include microworlds and simulations [61], where users can explore interactively models of important concepts (such as the popular Interactive Physics); multiple linked representations [35] that help students appropriately understand the connections between representations which require some form of translation (such as educational uses of graphing calculators, which might link an algebraic representation to a Cartesian representation); and finally access to information that might otherwise be inaccessible or unwieldy (such as the digital version of the Physician's Desk Reference carried by many medical students on their Palm handheld computers). Many instructivist applications of technology for education might be described as applying this representation-oriented strategy or advantage in support of learning (trying to design optimal direct instruction), but cognitive and sociocultural learning theorists can make use of the computer's ability to improve representation of content, for instance through microworlds or instructional anchors for situating learning [55].

\subsection{Process Support}

The second class of advantages provided by information technology is the process advantage. This advantage reflects the 
ability of interactive technologies to scaffold tasks, procedures, or processes that learners encounter during learning [41, 64]. A computer or other technology might act as a gatekeeper, timekeeper, grader, or play a more complex role in the learner's actions and processes. The types of technology traditionally called task or performance support [49] might be used to aid in learning, either by helping a novice user complete a task in a domain that they might not otherwise be able to complete it (for instance, the "wizards" in Microsoft Office that walk a user through a procedural task in Microsoft Office's word processor or spreadsheet program), or by aiding a user in a scholarly task in another domain, such as the use of pervasive computing to support notetaking in class [10]. Some important processes that lead to learning like metacognition (thinking about, and monitoring, one's own thinking) might also be supported using a process approach, for instance, self-quizzes or checklists that might guide a student through a web-based course in Blackboard or WebCT, post-hoc video analysis of tennis swings, or reflection prompting systems such as those in the KIE software [2]. Much of the field of intelligent tutoring systems might be most appropriately categorized as employing a process strategy because they attempt to model and guide the user's problem solving activities. A more distal use of a process strategy might support teachers' tasks rather than students' [3]. This type of strategy might be used by instructivists to support students in either just-in-time instruction or to help with decoding materials, by cognitive construcitivists trying to reduce a student's cognitive load, or by sociocultural constructivists to support social scaffolding and appropriation processes.

\subsection{Social Context Support}

The third class of advantages provided by information technology in learning settings is the social context advantage. Technology may be employed to change or distort the social context in which the learner operates [57], in order to facilitate more or better learning [18]. For instance, communication networks might permit external experts to be brought in to school activities, changing the context of learning for the students. The student is no longer part of just a classroom exercise; they might be more authentically trying to impress an outsider. Or, technology might change the social context within the setting, for instance by allowing people to communicate anonymously and thereby with greater social safety, as with the Multimedia Forum Kiosk tool which was used to support gender equity in school science discussions [28]. Even noncommunication technologies may shift the learner's social context; for instance, technologies (such as role-playing software like the Sickle-Cell Anemia case used at the Museum of Science and Industry in Chicago [52]) may cause users to reconsider their own identity or relationship to others. A social context-oriented strategy might be used by an instructivist or a cognitivist to change the affect or motivational set of the learner; a sociocultural instructor might try to alter context to support legitimate peripheral participation or other cultural shifts.

The framework makes sense in the paradigm of distributed cognition because it focuses on how tools and computer-based representations can change a distributed system of individuals who are engaged in some sort of learning, concordant with our conception of knowledge building communities above. The framework focuses on how computers can improve the overall distributed cognitive system of users.
In summary, the boundaries between the three categories are not sharp, and many interventions use elements of all three of the framework's advantages as strategies for supporting learning. For instance, the SpeakEasy discussion tool enhances representations by structuring or visualizing postings in an innovative way [25], it supports a process of reflective contribution to discourse [24], and it changes students' social context by allowing anonymous participation with classmates [28].

This framework was intended to be general enough to encompass the new and advantageous affordances of technology generally, rather than a specific technology or new electronic medium. One useful property of the framework is that it is more general than a particular instructional strategy (say, cognitive apprenticeship) but specific enough to suggest new features in technology design.

\section{IMPLICATIONS FOR DESIGN}

Combining these two frameworks, we can imagine ways that technology design for distributed cognition can support each of the elements of the C4P model. Here we illustrate with examples from two Web-based online communities: CompanyCommand, and the CILT Knowledge Network.

CompanyCommand (www.companycommand.com) is an online community of practice for US Army officers that has been operating for five years. It brings together past, present, and future company commanders who are committed to becoming more effective, helping each other become more effective, and advancing their profession. The online site includes over 4,700 content objects, most of which were developed and contributed by its members; over 4,100 posts on its asynchronous discussion board; and numerous links to relevant content from other sources. Whereas company commanders typically have (face-toface) access to fewer than ten of their peers at their local organization, CompanyCommand brings together over 10,000 members from across the Army and globe. The site includes a comprehensive member directory and requires people to formally request membership.

CILTKN, the Center for Innovative Learning Technologies Knowledge Network, was an online community for people interested in learning technologies from four sectors: industry, $\mathrm{K}-12$ teaching, researchers or academics, and policymakers. The online site served as a knowledge repository or digital library for the community and culled information of several predetermined types such as bibliographic references, course syllabi, research projects, invitations to collaboration, job listings, a member directory, and the like. When it closed in 2003, the site supported over 10,000 users, including over 8,000 educators from K-12 schools. The site had over 20,000 knowledge objects, mostly personal profiles and bibliographic citations. Membership involved filling out profile information in an online form.

These two online communities supported different types of groups: in one case, members of a single organization; in the other case, members of hundreds of organizations. In CompanyCommand, users all share a common profession; in CILTKN, users shared a common interest but disparate professions. With CompanyCommand, the site supports online forums; with CILTKN, online forums were tried and discarded 
in favor of personal communication media (primarily email and phone.) In both cases, the sites supported users that were geographically distributed around the world.

\subsection{Supporting Representations across the Four C's}

Technology's power to provide innovative representations of information allows it to support content, conversation, connections, and information context in both sites. In both CompanyCommand and CILTKN, the technology permitted geographically dispersed members to share and search information by providing new, more easy access to content. CILTKN, in addition, supported structured types of content in easy-to-use formats, for instance allowing download of bibliographic references into software such as BibTeX or EndNote. The representational power also supported information context: in both sites, contributions were linked to the profiles of real people, so users could better interpret the postings or knowledge objects. Both sites used representations to support forming new connections. In CompanyCommand, users can see who is online and see those members' profiles. They can also search profiles to find individuals with whom they share something in common, and member profiles include links to all the knowledge that person has contributed and links to all other members who have viewed that profile. In CILTKN, users could not only search profiles, but they could also view a graphical visualization of who in the community had collaborated with whom, using the ReferralWeb system [30]. CompanyCommand directly represents conversations with a powerful forum tool, while CILTKN provided support for users to converse via email hotlinks and forwarding addresses hosted on the site, and allowed direct download of contact information in an electronic format suitable for email or address-book programs (as vCards). Both sites had some of the benefits we take for granted on the web: powerful search and distributed access.

\subsection{Process Support for the Four C's}

How do these two sites scaffold the processes around content, conversations, social connections, and information context? Each site takes a different approach to creating and disseminating content. CompanyCommand fosters a particular model of content contribution and refinement, with workflow support for proposing content, describing content through metadata descriptions, allowing moderators to suggest improvements, and finally posting and disseminating the content. New content and new conversations are featured on the front page, aiding users in locating the most recent materials. CILTKN used a different approach, aiming to streamline the likelihood that users could post and use content during their existing work practices. Using the concept of VLTIs, or Very Low Threshold Interfaces, users could search for content without opening a browser via Apple's Sherlock technology. In addition, CILTKN used a "capture-at-the-source" model to streamline data entry: information such as bibliographic citations were captured through the conference submission process in order to facilitate later dissemination, and where possible automated sources of information (such as mailing lists for profile information) were pre-entered, so that if a user tried to register but was known or partially known to the system, they would have less data to enter. Technology can support other kinds of processes too. For instance, to facilitate information context, users of CompanyCommand are prompted to provide metadata descriptions for knowledge objects they wish to share, and knowledge objects can be linked to and nested within other, related knowledge objects. Connection-forming was fostered by both sites using periodic highlighted profiles of users, often connected to content they provided-in CILTKN this occurred through an email newsletter, and on CompanyCommand by highlighting the member on the Website's front page.

\subsection{Improving the Social Context of Learning via the Four C's}

Technology permitted the social context or milieu of members of both sites to improve. CompanyCommand uses a "multipleperspectives" approach, combined with a strong preference towards professionalism, to improve users' social context. Novices commingle with experts, and authoritative answers on the site are few. Rather, a particular issue, for instance, how to handle the death of a soldier in the unit, is explored from a variety of viewpoints. These perspectives are largely presented unmediated, in first-person form, a stark contrast to other more formal mechanisms for knowledge sharing in the Army. A focus on sharing stories (both through conversation and more formal knowledge objects such as video interviews) allows a particular kind of information context to be supported. Conversations are fostered based on topical interest, and can (and have) allowed users to meet and make new connections, even when they are already physically collocated. CILTKN, on the other hand, shifted context in a different way, by linking disparate constituencies. The structured data in the system served as an important kind of boundary object between, for instance, researchers and teachers. Not only did users have access to each others' content, but visualizations such as the ReferralWeb software, which showed bibliographic references in a social network diagram of coauthorship relationships, allowed users to get a sense of information context by linking the content to the social context in which it was produced. Furthermore, connections and conversation were fostered by providing an entire section of the site for requesting collaborators. These collaboration notices were almost entirely directed across traditional community boundaries (for instance, a teacher requesting a collaboration with a developer to apply for a technology grant to create tools for his/her classroom.)

\subsection{Designing for Distributed Cognition and C4P}

In this section, we have seen ways that the four C's-content, conversation, connections, and information context-can be supported using a design for distributed cognition framework. Representations, process support, and shifts in the learner's social context can help support the functioning of knowledgebuilding communities of practice.

It is worthy of note that technology enabled both of our example communities to function; it is difficult to imagine the activities that took place in these communities happening via letters, books, and face-to-face conversation-the distances are too great, the content evolves too quickly. While the literature on communities of practice suggests that they existed offline long before they did online (see for instance, Lave's work on tailors in Liberia [37]), recent attempts to document communities of 
practice assume that the community will exist partially, if not primarily, online. Technology has had a profound effect in enabling knowledge-building communities to scale up to large, geographically distributed communities. For instance, scholarly societies, the prototypical knowledge building communities, once functioned on a national or regional level, but are now frequently global in scale (see http://www.scholarlysocieties.org/, the scholarly societies project at the University of Waterloo). Technology has been identified as a way to help groups boost their collective intelligence [13, 14] through networked improvement communities, which are, in effect, knowledge-building communities across many organizations.

While not all learning takes place in communities, communities do appear to be an important mechanism for generation and dissemination of knowledge. In the fields of CSCW and CSCL, the core challenge is linking design challenges at the individual level to outcomes (especially learning) at the collective level. We believe that this challenge may be addressed with the two frameworks above. C4P identifies features of a functioning knowledge-building community. And the design for distributed cognition framework provides a starting place for designing for individuals' learning needs in a collaborative system. Combining the two is suggestive for design, and additionally, may help provide insights into evaluation and assessment of not only individual learning but the health of communities of practice.

\section{ACKNOWLEDGMENTS}

We thank those who helped us refine the frameworks above, and the members and leaders of the online communities we described. Portions of this work were funded by the National Science Foundation under grants EIA-9720384, REC-0231981 and CLT-0334199.

\section{REFERENCES}

[1] Allee, V. The Future of Knowledge: Increasing Prosperity Through Value Networks. Butterworth-Heinemann, New York, 2003.

[2] Bell, P., Davis, E.A. and Linn, M.C. The Knowledge Integration Environment: Theory and design. in Goldman, S. and Greeno, J. Eds. Computer Supported Collaborative Learning '95, ACM, Bloomington, Indiana, 1995, 14-21.

[3] Brooks-Young, S. and Simkins, M. The curriculum management creatures Technology and Learning, 1999, 10.

[4] Brown, J.S., Collins, A. and Duguid, P. Situated cognition and the culture of learning. Educational Researcher, 18 (1). 32-41.

[5] Brown, J.S. and Duguid, P. The social life of information. Harvard Business School Press, Boston, 2000.

[6] Case, R. and Bereiter, C. From behaviorism to cognitive behaviorism to cognitive development: Steps in the evolution of instructional design. Instructional Science, 13. 141-158.

[7] Chi, M.T.H., de Leeuw, N., Chiu, M.-H. and LaVancher, C. Eliciting self-explanations improves understanding. Cognitive Science, 18 (3). 439-477.
[8] Cohen, P.R., Integrated interfaces for decision-support with simulation. in 1991 Winter Simulation Conference Proceedings (Cat. No.91CH3050-2), (New York, NY, USA, 1991), IEEE, 1066-1072.

[9] Constant, D., Kiesler, S. and Sproull, L. What's Mine is Ours, or Is It? A Study of Attitudes about Information Sharing. Information Systems Research, 5 (4). 400-421.

[10] da Graca Pimentel, M., Ishiguro, Y., Abowd, G.D., Kerimbaev, B. and Guzdial, M. Supporting educational activities through dynamic web interfaces. Interacting with computers, 13 (3). 353-374.

[11] Dixon, N.M., Allen, N., Burgess, T., Kilner, P. and Schweitzer, S. CompanyCommand: Unleashing the Power of the Army Profession. Center for the Advancement of Leader Development and Organizational Learning, West Point, N.Y., 2005.

[12] Ellis, C.A. and Rein, G. Groupware: some issues and experiences. Communications of the ACM, 34 (1). 39-58.

[13] Engelbart, D. Boosting collective IQ: Bootstrapping CSCL. Hoadley, C. and Roschelle, J. eds. Computer Support for Collaborative Learning (CSCL) 1999, Stanford University, Palo Alto, CA, 1999.

[14] Engelbart, D.C. A Conceptual Framework for the Augmentation of Man's Intellect. Vistas in Information Handling.

[15] Forsythe, G.B., Hedlund, J., Snook, S., Horvath, J.A., Williams, W.M., Bullis, R.C., Dennis, M. and Sternberg, R., Construct validation of tacit knowledge for military leadership. in Annual Meeting of the American Educational Research Association, (San Diego, CA, 1998), American Educational Research Association.

[16] Gibbons, M., Limoges, C., Nowotny, H., Schwartzman, S., Scott, P. and Trow, M. The new production of knowledge: the dynamics of science and research in contemporary societies. SAGE Publications, Thousand Oaks, CA, 1994.

[17] Goman, K. Why People Don't Share What They Know Link\&Learn Newsletter, 2002.

[18] Goodenow, C. Strengthening the links between educational psychology and the study of social contexts. Educational Psychologist, 27 (2, Special Issue on the Nature and Mission of Educational Psychology). 177-196.

[19] Greenberg, S. (ed.), Computer-supported cooperative work and groupware. Harcourt Brace Jovanovich, San Diego, CA, 1991.

[20] Grudin, J. Groupware and social dynamics: eight challenges for developers. Communications of the ACM, 37 (1). 92-105.

[21] Harasim, L.M. Learning networks: a field guide to teaching and learning online. MIT Press, Cambridge, Mass., 1995.

[22] Hewitt, J. and Scardamalia, M. Design principles for distributed knowledge building processes. Educational Psychology Review, 10 (1). 75-96. 
[23] Hiltz, S.R. and Turoff, M. The network nation: Human communication via computer. MIT Press, Cambridge, Mass., 1993.

[24] Hoadley, C. Shaping social interactions for knowledge integration through technology. in Nichols, B.K., Kemp, A.C. and Jackson, D. eds. 71st NARST Annual Meeting, National Association for Research in Science Teaching, San Diego, California, 1998, 166.

[25] Hoadley, C. and Enyedy, N. Between information and collaboration: Middle spaces in computer media for learning. in Hoadley, C. and Roschelle, J. eds. CSCL '99: Proceedings of Computer Supported Collaborative Learning 1999, Lawrence Erlbaum Associates, Hillsdale, NJ, 1999, 242-250.

[26] Hoadley, C. and Hsi, S. Two perspectives on using multimedia in education -- Multimedia: a chance for change CPSR Newsletter (Computer Professionals for Social Responsibility), 1994, 10-13.

[27] Hoadley, C. and Kim, D.E. Learning, Design, and Technology: Creation of a design studio for educational innovation. in Palma dos Reis, A. and Isaís, P. eds. Proceedings of the IADIS International Conference eSociety 2003, International Association for the Development of the Information Society IADIS, Lisbon, Portugal, 2003, 510-519.

[28] Hsi, S. and Hoadley, C. Productive discussion in science: gender equity through electronic discourse. Journal of Science Education and Technology, 10 (1). 23-36.

[29] Hutchins, E. Cognition in the Wild. MIT Press, Cambridge, Massachusetts, 1995.

[30] Kautz, H., Selman, B. and Shah, M. The hidden web. AI Magazine, 18 (2). 27-36.

[31] Kilner, P.G. The Con-4P Model of Learning Design for Professional Communities. In Nall, J. and Robson, R. eds. Proceedings of E-Learn 2004, Association for the Advancement of Computing in Education, Norfolk, VA, 2004, 1307-1311.

[32] Kilner, P.G. Transforming Army Learning Through Communities of Practice. Military Review (May-June, 2002). 21-27.

[33] Kozma, R. Learning with media. Review of Educational Research, 61 (2). 179-211.

[34] Kozma, R.B. Will media influence learning? Reframing the debate. Educational Technology Research \& Development, 42 (2). 7-19.

[35] Kozma, R.B., Russell, J., Jones, T., Marx, N. and Davis, J., The Use of Multiple, Linked Representations to Facilitate Science Understanding. in EARLI Conference, (Aix-enProvence, France, 1993).

[36] Lave, J. Cognition in practice. Cambridge University Press, New York, NY, 1987.

[37] Lave, J. and Wenger, E. Situated learning: Legitimate peripheral participation. Cambridge University Press, New York, 1991.
[38] Mantovani, G. Social context in HCI: A new framework for mental models, cooperation, and communication. Cognitive Science, 20 (2). 237-269.

[39] Molnar, A.R. Computers in education: a brief history T.H.E. Journal, 1997, 63-68.

[40] Najjar, L.J. Multimedia information and learning. Journal of educational multimedia and hypermedia, 5 (2). 129-150.

[41] Newman, D., Griffin, P. and Cole, M. The construction zone: Working for cognitive change in school. Cambridge University Press, New York, 1989.

[42] Nonaka, I. The Knowledge-Creating Company. in Harvard Business Review on Knowledge Management, Harvard Business Review Press, Cambridge, MA, 1998, 21-46.

[43] Orr, J.E. Sharing knowledge, celebrating identity: Community memory in a service culture. in Middleton, D. and Edwards, D. eds. Collective remembering, Sage Publications, Newbury Park, CA, 1990, 169-189.

[44] Pea, R.D. Practices of distributed intelligence and designs for education. in Salomon, G. ed. Distributed Cognitions: psychological and educational considerations, Cambridge University Press, New York, 1993, 47-87.

[45] Peterson, C., Maier, S.F. and Seligman, M.E.P. Learned helplessness: a theory for the age of personal control. Oxford University Press, New York, 1993.

[46] Piaget, J. Piaget's Theory. in Mussen, P. ed. Carmichael's Manual of Child Psychology, Wiley, New York, 1970, pp. 703-732.

[47] Renninger, K.A. and Shumar, W. Building virtual communities: learning and change in cyberspace. Cambridge University Press, New York, 2002.

[48] Rheingold, H. The virtual community: homesteading on the electronic frontier. HarperPerennial, New York, NY, 1994.

[49] Rosenberg, M.J. Performance technology, performance support, and the future of training: A commentary. Performance improvement quarterly, 8 (1). 94-99.

[50] Saint-Onge, H. and Wallace, D. Leveraging communities of practice for strategic advantage. Butterworth-Heinemann, Boston, 2003.

[51] Salomon, G. Distributed cognitions: Psychological and educational considerations. Cambridge University Press, New York, 1997.

[52] Schank, R.C. and Cleary, C. Engines for Education. Lawrence Erlbaum Associates, Mahwah, NJ, 1995.

[53] Skinner, B.F. The technology of teaching. Prentice-Hall, Englewood Cliffs, NJ, 1968.

[54] Spiro, R.J. and Jehng, J.-C. Cognitive flexibility and hypertext: theory and technology for the nonlinear and multidimensional traversal of complex subject matter. in Nix, D. and Spiro, R.J. eds. Cognition, education, and multimedia: exploring ideas in high technology, Lawrence Erlbaum Associates, Hillsdale, NJ, 1990, 163-205.

[55] The Cognition and Technology Group at Vanderbilt Anchored instruction and its relationship to situated cognition. Educational Researcher (September). pp. 2-10. 
[56] Toffler, A. Future shock. Random House, New York,, 1970.

[57] Vaske, J.J. and Grantham, C.E. Socializing the humancomputer environment. Ablex, Norwood, New Jersey, 1990.

[58] Vygotsky, L.S. Mind in Society: The Development of Higher Psychological Processes. Harvard University Press, Cambridge, MA, 1974.

[59] Wenger, E. Communities of Practice: Learning, meaning, and identity. Cambridge University Press, Cambridge, UK, 1998.

[60] Wenger, E. C. and Snyder, W. M. Communities of practice: the organizational frontier..Harvard Business Review, (JanFeb 2000), 139-145.

[61] White, B.Y. ThinkerTools: Causal models, conceptual change, and science education. Cognition and Instruction, 10 (1). 1-100.
[62] Winograd, T., Groupware: the next wave or just another advertising slogan? in COMPCON Spring '89. ThirtyFourth IEEE Computer Society International Conference: Intellectual Leverage (IEEE Cat. No.89CH2686-4), (San Francisco, CA, USA, 1989), IEEE Comput. Soc. Press, 198-200.

[63] Winograd, T. Where the action is (groupware). BYTE, 13 (13). 256-258.

[64] Wood, D., Bruner, J.S. and Ross, G. The role of tutoring in problem solving. Journal of child psychology and psychiatry and allied disciplines, 17 (2). 89-100.

[65] Woodruff, E.E. Concerning the Cohesive Nature of CSCL Communities. in Hoadley, C. and Roschelle, J. eds. Proceedings of Computer Supported Collaborative Learning '99 Conference, Lawrence Erlbaum Associates, Mahwah, NJ, 1999, 677-680. 